\title{
EDITORIAL
}

\section{Lower respiratory tract infection: variation in care, disease definitions, and the nature of primary care}

See linked article by Greene et al.

on pg 299

\section{*Chris van Weel ${ }^{\mathrm{a}}$}

a Professor of Family Medicine and Head of Department, Department of Primary and Community Care, Radboud University Nijmegen Medical Center, The Netherlands

\section{*Correspondence:}

Professor Chris van Weel

Department of Primary and Community Care,

Radboud University Nijmegen Medical

Center,

117-hag,

PO Box 9101, 6500HB Nijmegen,

The Netherlands

Tel. +3124616332

Fax +3124354 1862

E-mail: c.vanWeel@elg.umcn.nl

Commissioned article

Not externally peer-reviewed

Accepted 19th July 2011

Online 2nd August 2011
In this issue of the PCRJ, Greene et al.' report an elaborate study to define lower respiratory tract infections (LRTIS). Their study is triggered by the observation of substantial variation in care, ${ }^{2}$ with potentially grave consequences for individuals and populations. Better understanding of why practitioners (in this case general practitioners [GPs]) differ in their treatment and management is needed before strategies can be designed to curtail undue variation of care. Clarifying the nature of health problems that are encountered - like LRTIs - will help to find common ground and facilitate professional discourse. Definitions play an important role in this. In fact, this goes back to the early days of academic primary care, where morbidity surveys ${ }^{3,4}$ laid the foundation of what, three or four decades later, has become a strong academic discipline. Effort to find definitions marks the emergence of a common frame of reference. ${ }^{5}$ In that respect, the process that Greene et al. describe may be as important as the results they present.

The concept behind their study appears to be that a better definition of the disease spectrum which GPs encounter will help to clarify GPs' performance and help understand their differences in approach. With due respect for the quality of this study, it remains questionable as to what extent this will be effective. In this sense, one needs to review the question of the effectiveness of primary care - in particular, the "paradox of primary care". ${ }^{6}$

Historically, diagnoses and diseases take centre stage in medical care, together with the teaching, education and research associated with it. Within a defined disease perspective particularly when using disease-specific process of care outcomes - specialists may achieve slightly better results compared to GPs/generalists. ${ }^{7}$ This has been documented for a variety of specialties and organ systems, ${ }^{6}$ including the respiratory tract. ${ }^{8.11}$ However, when disease process is not used as an outcome but rather the outcome is patients' functional health status, specialists and generalists achieve similar effects - with generalists using fewer resources ${ }^{12,13}$ and thus representing greater value. ${ }^{6.14}$ Consequently, primary care is associated with better population health and life expectancy ${ }^{15,16}$ and with better ways of controlling major (chronic) diseases on a population level, ${ }^{17}$ costs are lower and health care obtains greater equity.

Thus, the paradox of primary care is that, compared with specialty care or with systems dominated by specialty care, primary care is associated with the following:

(1) apparently poorer quality care for individual diseases, yet

(2) similar functional health status at lower cost for people with chronic disease, and

(3) better quality, better health, greater equity, and lower cost for whole people and populations.

These findings send a strong message. The concept of the disease as the key determinant of medical performance, and the organisation of care in a framework of disease-related expertise, are in itself insufficient to cope successfully with the health needs of people and populations. In other words, the vertical disease-based structure of response to important health challenges should be replaced by a horizontal one in which integrated primary care takes the lead and co-ordinates the role and contribution of more specialised expertise. ${ }^{18}$ This principle is particularly important in the quest to respond to the challenge of noncommunicable diseases, where a repetition of disease-oriented consortia should be avoided. ${ }^{19}$ 
The paradox of primary care ${ }^{6}$ poses an interesting challenge, in that it is of paramount importance to understand why primary care is different. One can expect this to be related to values like comprehensiveness and continuity of care, focus on the person(s) with the disease within their psychosocial context, and in the context of a relationship of trust over time - core values, deeply rooted in the professionalism of general practice and primary care. ${ }^{20}$ The best approach for people with (chronic) conditions is (in all probability) shared care between specialists and generalists, ${ }^{21}$ as long as primary care is being empowered through that collaboration to employ its core values and co-ordinate specialist contribution. ${ }^{19}$

This brings us back to the issue of the variation in primary care management of patients with LRTIs. Given the nature of this spectrum of infections, there is an urgent need to establish in detail the contribution provided by continuity of care, person-centeredness, and responsiveness to the psychosocial context in which the patient finds himself/herself, as well as their relationship to the outcome of care. Here, there is a need for better understanding - and a common frame of reference is needed.

\section{Conflicts of interest}

None.

\section{References}

1. Greene G, Hood K, Little P, et al. Towards clinical definitions of lower respiratory tract infection (LRTI) for research and primary care practice in Europe: an international consensus study. Prim Care Respir J 2011;20(3):299-306. http://dx.doi.org/10.4104/pcrj.2011.00034

2. Butler CC, Hood, K, Verheij T et al. Variation in antibiotic prescribing and its impact on recovery in patients with acute cough in primary care: prospective study in 13 countries. BMJ 2009;338:b2242. http://dx.doi.org/10.1136/bmj.b2242

3. van Weel $C$. The Continuous Morbidity Registration Nijmegen: Background and history of a Dutch general practice database. Eur J Gen Pract 2008;14(suppl 1): 5-12. http://dx.doi.org/10.1080/13814780802436028

4. Hodgkin K. Towards early diagnosis in primary care. Edinburgh: Churchill Livingstone, 1978.

5. Anonymous. IDHPPC-2 defined. Inclusion criteria for the use of the rubrics of the International Classification of Health Problems in Primary Care. Oxford: Oxford University Press, 1983.

6. Stange KC, Ferrer RL. The Paradox of Primary Care. Ann Fam Med 2009;7:2939. http://dx.doi.org/10.1370/afm. 1023

7. Smetana GW, Landon BE, Bindman AB, et al. A comparison of outcomes resulting from generalist vs specialist care for a single discrete medical condition: a systematic review and methodologic critique. Arch Intern Med 2007;167(1):10-20. http://dx.doi.org/10.1001/archinte.167.1.10
8. Vollmer WM, O'Hollaren M, Ettinger KM, et al. Specialty differences in the management of asthma. A cross-sectional assessment of allergists' patients and generalists' patients in a large HMO. Arch Intern Med 1997;157(11):1201-08. http://dx.doi.org/10.1001/archinte.157.11.1201

9. Janson S, Weiss K. A national survey of asthma knowledge and practices among specialists and primary care physicians. J Asthma 2004;41(3):343-8. http://dx.doi.org/10.1081/JAS-120026093

10. Diette GB, Skinner EA, Nguyen TT, Markson L, Clark BD, Wu AW. Comparison of quality of care by specialist and generalist physicians as usual source of asthma care for children. Pediatrics 2001;108(2):432-7. http://dx.doi.org/ 10.1542/peds.108.2.432

11. Backer V, Nepper-Christensen S, Nolte H. Quality of care in patients with asthma and rhinitis treated by respiratory specialists and primary care physicians: a 3-year randomized and prospective follow-up study. Ann Allergy Asthma Immunol 2006;97(4):490-6. http://dx.doi.org/10.1016/S10811206(10)60940-4

12. Greenfield S, Rogers W, Mangotich M, Carney MF, Tarlov AR. Outcomes of patients with hypertension and non-insulin dependent diabetes mellitus treated by different systems and specialties. Results from the medical outcomes study. JAMA 1995;274(18):1436-44. http://dx.doi.org/10.1001/jama.274.18.1436

13. Greenfield S, Nelson EC, Zubkoff M, et al. Variations in resource utilization among medical specialties and systems of care. Results from the medical outcomes study. JAMA 1992;267(12):1624-30. http://dx.doi.org/10.1001/jama.267.12.1624

14. Rosenblatt RA. Specialists or generalists. On whom should we base the American health care system? JAMA 1992;267(12):1665-6. http://dx.doi.org/ 10.1001/jama.267.12.1665

15. Franks P, Fiscella K. Primary care physicians and specialists as personal physicians. Health care expenditures and mortality experience. J Fam Pract 1998;47:105-09

16. Shi L, Macinko J, Starfield B, Politzer R, Wulu J, Xu J. Primary care, social inequalities, and all-cause, heart disease, and cancer mortality in US counties, 1990. Am J Public Health 2005;95(4):674-80. http://dx.doi.org/ 10.2105/AJPH.2003.031716

17. Macinko, J. Starfield, B. L. Shi. (2007). Primary Care Physician Supply and Health Outcomes in the United States: a Meta-analysis. International Journal of Health Services 2007;31:111-26. http://dx.doi.org/10.2190/3431-G6T7-37M8-P224

18. De Maeseneer J, van Weel C, Egilman D, et al. Funding for primary health care in developing countries. BMJ 2008;336:518-19. http://dx.doi.org/10.1136/ bmj.39496.444271.80

19. De Maeseneer J, Roberts RG, Demarzo M, et al. Tackling the NCDs: a different approach is needed. Lancet 2011, accepted for publication.

20. Wonca Europe. The European definition of general practice/family medicine. Wonca Europe 2002. The European Definition of General Practice/Family Medicine (accessed July 13, 2011)

21. Meulepas MA, Jacobs JE, Smeenk FW, et al. Effect of an integrated primary care model on the management of middle-aged and old patients with obstructive lung diseases. Scand J Prim Health Care 2007;25(3):186-92. http://dx.doi.org/10.1080/02813430701573943

Available online at http://www.thepcrj.org 